Document downloaded from:

http://hdl.handle.net/10251/44627

This paper must be cited as:

Borrell Tomás, MA.; Salvador Moya, MD.; Rocha, VG.; Fernández, A.; Molina, T.; Moreno, R. (2013). EPD and Spark Plasma Sintering of bimodal alumina/titania concentrated suspensions. Journal of Alloys and Compounds. 577:195-202. doi:10.1016/j.jallcom.2013.04.175.

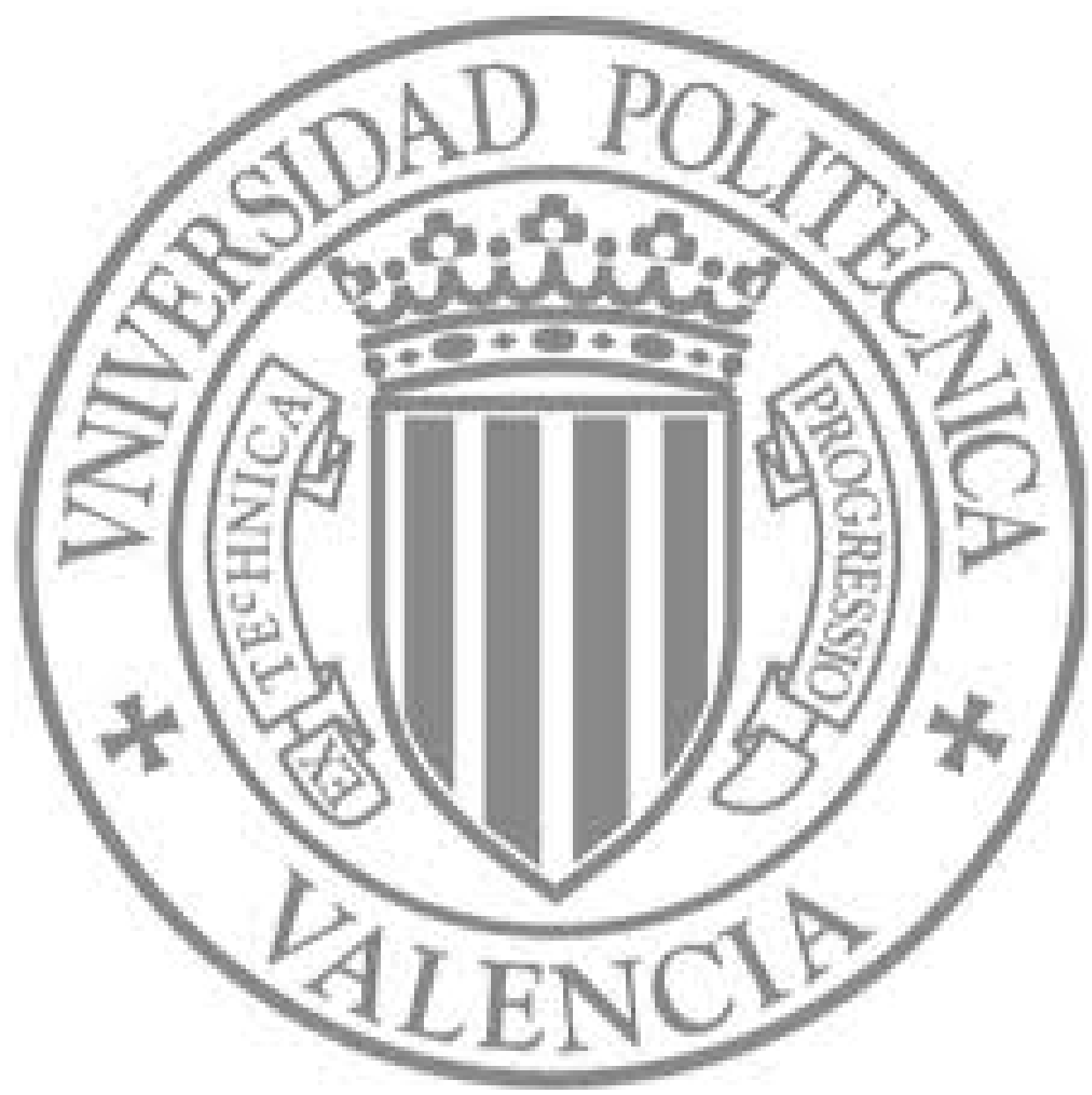

The final publication is available at

http://dx.doi.org/10.1016/j.jallcom.2013.04.175

Copyright Elsevier 


\title{
EPD and Spark Plasma Sintering of bimodal alumina/titania concentrated
}

\section{suspensions}

\author{
Amparo Borrell*¹, María Dolores Salvador ${ }^{1}$, Victoria G. Rocha ${ }^{2}$, Adolfo Fernández ${ }^{2,3}$, \\ Tamara Molina ${ }^{4}$, Rodrigo Moreno ${ }^{4}$
}

\author{
${ }^{1}$ Instituto de Tecnología de Materiales (ITM), Universidad Politécnica de Valencia (UPV), Camino \\ de Vera s/n, 46022 Valencia, Spain \\ ${ }^{2}$ ITMA Materials Technology, Parque Tecnológico de Asturias, 33428 Llanera, Spain \\ ${ }^{3}$ Centro de Investigación en Nanomateriales y Nanotecnología (CSIC-UO-PA), Parque Tecnológico \\ de Asturias, 33428 Llanera, Spain \\ ${ }^{4}$ Instituto de Cerámica y Vidrio (ICV-CSIC), E-28049 Madrid, Spain
}

\begin{abstract}
*Corresponding author. Address: Instituto de Tecnología de Materiales (ITM), Universidad Politécnica de Valencia (UPV), Camino de Vera s/n, 46022 Valencia, Spain. Tel.: +34 963877 007; Fax: +34 963877 629. E-mail address: aborrell@upvnet.upv.es (A. Borrell)
\end{abstract}

\begin{abstract}
Alumina-aluminium titanate (A-AT) composites and laminates have been recently investigated because they can provide improved flaw tolerance and toughness associated to a microcracking mechanism. A-AT composites have been produced by slip casting and reaction sintering of submicron sized alumina and titania powders. This work deals with the preparation of thick selfsustained A-AT films from mixtures of submicron sized alumina and nano sized titania powders and further sintering by conventional and non-conventional (spark plasma sintering, SPS) methods. Suspensions were prepared in water to high solid loadings, up to 50 vol.\%. Self-sustained films were obtained by aqueous electrophoretic deposition (EPD) using graphite substrates under constant
\end{abstract}


current density conditions. The evolution of mass per unit area with current density and deposition time was recorded. The films were characterized in the green state and after sintering at different temperatures (1300-1400) ${ }^{\circ} \mathrm{C}$. Fully dense A-AT reaction sintered materials were obtained at low temperature by SPS.

Keywords: Ceramics; EPD; mechanical properties; Spark plasma sintering

\section{Introduction}

Dense alumina-aluminium titanate composites with controlled microstructure have been fabricated from alumina and previously reacted aluminium titanate powders [1,2] and by reaction sintering of alumina $\left(\mathrm{Al}_{2} \mathrm{O}_{3}\right)$ and titania $\left(\mathrm{TiO}_{2}\right)$ mixtures $[3,4]$. However, the microstructures obtained by reaction sintering usually display low as-fired densities, abnormal grain growth and, even unreacted titania particles, owing to the special characteristics of the alumina-titania (AT) reaction process [5]. Previous studies have shown that colloidal processing allows dense, homogeneous A-AT materials to be obtained by reaction sintering of green bodies produced by slip casting of suspensions with controlled mixtures of alumina and titania [6]. It has been shown that the main toughening mechanism in composites with 10 vol.\% AT was microcracking, so that the use of nanosized titania to produce nanometric particles of AT in the matrix should provide enhanced properties. However, the use of nanosized particles to promote the formation of nanocomposites has drawn little attention, due to the inherent difficulties arising from the dispersion of the nanosized phase into the matrix. However, the use of fast firing techniques such as SPS has demonstrated to be a suitable way to produce dense $\mathrm{A} / \mathrm{AT}$ materials by reaction sintering using nanopowders $[7,8]$. To improve the dispersion of such nanoparticles one possible route is the colloidal filtration, which has been also explored recently to obtain dense A/AT materials $[9,10]$. Recently, we have described also the possibility to obtain dense A/AT materials by a spark plasma reaction sintering (SPS) process using cast green bodies instead of the conventional mixture of powders [11]. This method has the 
advantage that the components of the mixture have been already dispersed and shaped to a green body with high particle packing.

Although this methodology has been successfully used for bulk bodies the possibility of obtaining films using SPS needs to be explored. One of the most common methods to produce thick coatings and films is by electrophoretic deposition (EPD) using particulate sols and suspensions. It is a simple, versatile forming route with the advantage that diluted suspensions can be used, whereas most of the colloidal shaping methods make use of concentrated suspensions that are not always possible to prepare with the desired flowing properties. The EPD process can be controlled considering some properties related to the suspension itself (mainly conductivity and zeta potential) and, processing parameters (basically the maintenance of a constant electric field and the deposition time). The foundations of EPD and the modelling of kinetics have been described elsewhere $[12,13]$. In previous work, the processing parameters involved in the fabrication of A/AT films by EPD and reaction sintering in a conventional furnace has been reported [14], but reaction sintered materials had a limited relative density (by $95 \%$ of theoretical density) much lower than desired for structural applications. To increase the sintered density to near to theoretical values the use of nonconventional sintering methods is required.

SPS is a promising method which can work at heating rates of hundreds degrees per minute, reaching high temperatures in a short time, and producing dense materials [15]. These features allow the achievement of microstructures unattainable by other sintering methods and, therefore, obtain mechanical properties superior to those obtained using conventional techniques.

In the present investigation we report, for the first time, the reaction-sintering by fast SPS technique of green thick films prepared by EPD of alumina and titania powders for the fabrication in situ of $\mathrm{Al}_{2} \mathrm{O}_{3} / \mathrm{Al}_{2} \mathrm{TiO}_{5}$ ceramic composites. The stability of the concentrated suspension was studied from zeta potential and rheological measurements and controlling the deposition parameters, i.e. current density and deposition time.

The possibility of obtaining completely reacted and dense A-AT nanostructured composites at low 
temperature by reaction-sintering is studied in detail. The thick films were characterized in the green state and after sintering by conventional techniques and by SPS at different temperatures (1300-1400 $\left.{ }^{\circ} \mathrm{C}\right)$. The density measurements, mechanical properties, such as hardness by nanoindentation and, microstructure of the obtained ceramic composites are studied and compared with composites obtained by conventional sintering method.

\section{Materials and methods}

\subsection{Starting materials}

The following commercial powders were used as starting materials: 1) a submicron-sized, high purity $\alpha-\mathrm{Al}_{2} \mathrm{O}_{3}$ (Condea-Ceralox HPA-05, Sasol, USA) with a mean particle size of $0.35 \mu \mathrm{m}$ and specific surface area of $9.5 \mathrm{~m}^{2} \mathrm{~g}^{-1}$; and 2) a nanosized $\mathrm{TiO}_{2}$ powder (Aeroxide ${ }^{\circledR} \mathrm{P} 25$, DegussaEvonik, Germany) with an average primary particle size of $40 \mathrm{~nm}$, a specific surface area of $50 \mathrm{~m}^{2}$ $\mathrm{g}^{-1}$, and a relative ratio of anatase:rutile phases of 3:1. Mixtures (AT) of submicronic alumina (A) and nanometric titania $(\mathrm{T})$ were always prepared at a relative weight ratio of 87:13.

The specific surface area was determined using the single-point BET method (MonosorbTM Surface Area Analyzer MS-13, Quantachrome Corporation, USA) after degassing at $150{ }^{\circ} \mathrm{C}$. Particle size distributions were measured by laser diffraction (Mastersizer S, Malvern, UK) and dynamic light scattering (NanoZS, Malvern, UK) for submicrometric and nanometric particles, respectively.

\subsection{Preparation and characterization of suspensions}

The colloidal stability of aqueous suspensions of $\mathrm{TiO}_{2}$ nanopowders was studied in previous works by measuring the zeta potential as a function of deflocculant content and $\mathrm{pH}$ and the conductivity $[10,11]$. Concentrated suspensions were prepared to solids loadings of 30,40 and 50 vol.\% (i.e. 67 , 73 and 80 wt.\%) using deionized water. A commercial polyacrylic acid-based polyelectrolyte (DURAMAX $^{\mathrm{TM}}$ D-3005, Rohm \& Haas, USA) was used as a deflocculant. This was supplied as an 
aqueous solution of polyacrylic acid (PAA) with 35 wt. $\%$ active matter of PAA $\left[\left(\mathrm{C}_{3} \mathrm{H}_{4} \mathrm{O}_{2}\right)_{\mathrm{n}}\right]$ and an average molecular weight of 2400. Studies elsewhere have shown that this deflocculant is suitable for obtaining concentrated suspensions of both studied materials [16,17]. The suspensions were prepared by first adding the PAA required to disperse the nanosized titania particles (4 wt.\% PAA in relation to the titania content); the titania nanopowder was subsequently added and homogenized by sonication for $1 \mathrm{~min}$. The alumina powder was then added after the relative amount of PAA needed to disperse the submicronic alumina particles $(0.28 \mathrm{wt} . \%$ PAA in relation to the alumina content) had been added. The mixture was then maintained for 15 min under mechanical stirring. The foregoing PAA contents refer to the active matter concentration.

To improve the dispersion state, the as-prepared suspensions were sonicated for 1,3 and $5 \mathrm{~min}$ using an ultrasounds (US) probe (UP 400S, Dr Hielscher GmbH, Germany) in order to prevent agglomeration. The rheological behaviour of all suspensions was determined using a rheometer (Haake RS50, Thermo Scientific, Germany) operating at controlled shear rate (CR), increasing the shear rate from 0 to $1000 \mathrm{~s}^{-1}$ in $5 \mathrm{~min}$, with a 1 -min hold at $1000 \mathrm{~s}^{-1}$, and then decreasing the shear rate from 1000 to $0 \mathrm{~s}^{-1}$ in $5 \mathrm{~min}$. The measurements were performed at $25{ }^{\circ} \mathrm{C}$ using a double-cone and plate system.

\subsection{Deposition tests}

Electrophoretic deposition (EPD) experiments were performed in galvanostatic mode for deposition times of 1 to $10 \mathrm{~min}$ and applied current intensities of 1,3 and $5 \mathrm{~mA}$ (i.e., current densities of 0.28 , 0.83 and $1.39 \mathrm{~mA} \mathrm{~cm}^{-2}$, respectively), using a power source (Keithley, mod. 2611, USA). Graphite electrodes were used as electrodes, which were maintained at a separation distance of $2 \mathrm{~cm}$. The dipping area of the substrates was $\sim 3.6 \mathrm{~cm}^{2}$ considering that dipping occurred in both surfaces. Deposited substrates were extracted at a constant withdrawal rate of $4.5 \mathrm{~mm} \mathrm{~s}^{-1}$ (that is, $\sim 27 \mathrm{~cm}$ $\left.\min ^{-1}\right), \mathrm{pH}$ and conductivity were registered during the deposition process. 


\subsection{Sintering and characterization}

The films deposited by EPD at the best conditions were sintered by two procedures: under conventional sintering in an electric furnace and by fast sintering (SPS). In the case of conventional sintering, the graphite substrate burns out during the thermal treatment and two self-sustained films are obtained, one formed principally by EPD and the other mainly formed by dipping. Conventional sintering was carried out in air at different temperatures $\left(1300-1400{ }^{\circ} \mathrm{C}\right)$ using a heating rate of $5{ }^{\circ} \mathrm{C}$ $\min ^{-1}$ with $2 \mathrm{~h}$ of dwelling time at the maximum temperature.

A second set of EPD films was introduced into a 20-mm-diameter graphite die and sintered using an SPS apparatus HP D25/1 (FCT Systeme GmbH, Rauenstein, Germany) at temperatures from 1300$1400{ }^{\circ} \mathrm{C}$ and $80 \mathrm{MPa}$ of pressure to obtain fully sintered bulk materials. The tests were carried out under vacuum at a heating rate of $100{ }^{\circ} \mathrm{C} \min ^{-1}$ with a $1 \mathrm{~min}$ dwelling time at the maximum temperature.

In all cases, two different samples were prepared at the same conditions. The thickness of the sintered self-sustained films was measured by direct imaging by using a field emission gun scanning electron microscope (FE-SEM, HITACHI S-4800, SCSIE of the University of Valencia). Given values are the average of 10 measurements.

The densities of the sintered compacts were determined by the Archimedes method (ISO-3369) using distilled water. Theoretical densities (TD) were calculated using density values of $3.99 \mathrm{~g} \mathrm{~cm}^{-3}$ for alumina [18], $3.89 \mathrm{~g} \mathrm{~cm}^{-3}$ for $\mathrm{TiO}_{2}$ (anatase) [19], $4.25 \mathrm{~g} \mathrm{~cm}^{-3}$ for $\mathrm{TiO}_{2}$ (rutile) [20], and $3.70 \mathrm{~g}$ $\mathrm{cm}^{-3}$ for aluminium titanate [21]. The crystalline phases of the bulk ceramic composites were determined by X-ray diffraction (XRD, D8 Advance, Bruker, Germany). The measurements were performed in the $20^{\circ}-80^{\circ}$ range and the step size and time of reading were $0.02^{\circ}$ and $0.3 \mathrm{~s}$, respectively.

The hardness measurements of the sintered discs were analyzed using a Nanoindenter device (G200 Agilent Tech., USA). Indentations were performed on the surface of samples previously polished with $0.25 \mu \mathrm{m}$ diamond abrasives and using a calibrated diamond Berkovich tip. Tests were 
conducted using Continuous Stiffness Measurement (CSM) at $2 \mathrm{~nm}$ and $45 \mathrm{~Hz}$ harmonic oscillations. Microstructural characterisation on polished and thermally etched (at $100{ }^{\circ} \mathrm{C}$ below the sintering temperature) surfaces and the fracture surface sections of the sintered samples have been observed by FE-SEM.

\section{Results and discussion}

According to a previous work the isoelectric points of $\mathrm{Al}_{2} \mathrm{O}_{3}$ and $\mathrm{TiO}_{2}$ occurred at $\mathrm{pH}$ values of 9 and 7 , respectively [10]. To improve stability at moderate and basic $\mathrm{pH}$ values, PAA was added as a deflocculant to active matter contents of 0.28 and 4 wt.\% for A and T, respectively. The addition of PAA shifted the isoelectric points down to $\mathrm{pH}$ values of $\sim 4$ and $<3$, respectively.

Figures 1a, 1b, and 1c show the flow curves of suspensions prepared to different solids loadings of 30, 40 and 50 vol.\%, respectively, before and after homogenization with US probe for different mixing times. Suspensions prepared to 30 vol.\% solids have very low viscosity, even those prepared by simple agitation without ultrasound treatment, which have a small thixotropic cycle. The application of US during $1 \mathrm{~min}$ reduces the viscosity and avoids the thixotropy. Viscosity obviously increases with increasing solids contents, especially for suspensions without US treatment. The dispersion is largely improved by sonication, which not only reduces the viscosity but also the thixotropic cycles. Viscosity decreases with US up to $3 \mathrm{~min}$, and increases again with further sonication. Hence, all suspensions used for further studies were prepared by mixing with US for 3 $\min$.

EPD tests were performed with AT suspensions prepared to 30, 40 and 50 vol.\% solids and the weight per unit area of deposits obtained at different current densities and deposition times were measured. Figure 2 shows the deposited mass per unit area as a function of deposition time for EPD tests performed at constant current intensities of 1,3 and $5 \mathrm{~mA}$ (i.e., current densities of $0.28,0.83$ and $1.39 \mathrm{~mA} \mathrm{~cm}^{-2}$, respectively) with the suspensions prepared to the three solids contents (figures 
$2 \mathrm{a}, 2 \mathrm{~b}$ and $2 \mathrm{c}$, for 30,40 , and 50 vol.\%, respectively). In spite of the large thickness of the deposits, a nearly linear variation of deposited mass can be seen in most cases. This is expected considering the short deposition times considered in this work, since deviations to the linearity with an S-shape are usually observed in the EPD of concentrated suspensions and sols at longer deposition times $[22,23]$. The growing kinetics directly increases with both the current density of the applied electric field and with the solids loading of the suspension. Different series of experiments were performed for any condition, showing an excellent reproducibility. Deviations were only observed in the case of the most concentrated suspensions due to the heaviness of the deposits and their large thickness, difficulty to remain attached to the substrate and to maintain uniformity. Furthermore, these suspensions are highly concentrated and their viscosity is very high. This strongly affects the electrophoretic mobility of the particles and makes the motion of the particles more difficult. Furthermore, the removal of bubbles originating from the electrodes of aqueous water during EPD could be observed during the tests and in the green samples.

No variation of $\mathrm{pH}$ was experimentally observed during EPD tests for any suspension, although some differences were observed depending mainly on the solids loading, with values about $\mathrm{pH}$ 8.99.0 for 30 and 40 vol.\% suspensions, and slightly lower (8.5) for 50 vol.\% solids. Similarly, the suspension conductivity maintained constant during the consecutive EPD tests, although the conductivity of 30 vol.\% suspensions was lower (below $3.5 \mathrm{mS} \mathrm{cm}^{-1}$ ) than that of the other two suspensions (with values of about $4.2 \mathrm{mS} \mathrm{cm}^{-1}$ ).

The use of such concentrated suspensions led to the formation of very thick deposits at both sides of the EPD substrate and not only on the surface in face to the counter electrode. The differences between the deposition at the front surface and the back surface of the electrode cannot be evaluated in the green state, as both are still attached to the substrate and they do not have the mechanical strength needed for machining prior to microscopy observations. Thus, coated graphite films were calcined at temperatures of 1300,1350 , and $1400{ }^{\circ} \mathrm{C}$ in conventional furnace in order to remove the graphite layer, so that two self-supported films can be separated. 
Figure 3 shows a cross-section picture of the frontal and back films obtained from the suspension with 30,40 and 50 vol.\% AT by EPD at $5 \mathrm{~mA}$ (i.e. $1.39 \mathrm{~mA} . \mathrm{cm}^{-2}$ ) for $10 \mathrm{~min}$ and conventionally sintered at $1400{ }^{\circ} \mathrm{C}$. The pictures demonstrate that the front surface is thicker but only by a 50 vol.\% with respect to the back one. This could be attributed to the strong contribution to the film thickness due to simply dipping, but the low mass per unit area measured for deposits obtained by dipping (points of zero deposition time in figure 2) demonstrate that the great thickness obtained by EPD is not due to dipping but there is a secondary effect of the electric field, probably related to the large number of interactions existing in these concentrated suspensions, where the viscosity is significantly higher and the electric field becomes strongly asymmetric and can produce counter flows within the EPD cell. This aspect, however, cannot be studied in depth in this work and needs further effort.

Similar findings can be drawn for the other suspensions. Figure 4 shows the variation of the thickness of sintered A-AT films (front and back layers) obtained from the different solids loadings suspensions as a function of the deposition time. Thicknesses were measured with the FE-SEM at different sections of the self-sustained films. The general shape of the curve seems to respond to a parabolic trend, where the difference of thickness between the front and the back layers increases for increasing deposition times. These data are only estimative because the errors are different for different samples due to the non-planarity of the surfaces and other changes due to variability of several processing steps.

Figure 5 compares the microstructure of front and back surfaces of deposits sintered at $1400{ }^{\circ} \mathrm{C}$. Pictures show a smooth surface according to a homogeneous deposition but the front layer shows clearly the presence of pores. The material shows large uniformity, demonstrating the good dispersion level, and the pores can be consequence of the bubbles formed during EPD in water. The EDX analysis demonstrates that bright dots contain the reacted aluminum titanate, while grey areas correspond to the alumina matrix. Figure 6 shows representative EDX spectra for both the bright and the dark areas confirming that statement. 
By SPS, the graphite substrate does not burn out because the sintering cycle occurs in vacuum. In this case, the two self-sustained films have been also obtained similarly to the conventional method. Figure 7 compares the aspect of the film obtained by SPS from a 40 vol.\% solid suspension after a thermal treatment at $1400{ }^{\circ} \mathrm{C}$. The thickness of the front layer is about $491 \pm 15 \mu \mathrm{m}$, whereas the back-side layer has a thickness of $347 \pm 10 \mu \mathrm{m}$. The films are rather homogeneous and have a smooth outer surface.

The XRD pattern of the bulk ceramic A-AT composites sintered by spark plasma sintering at 1300 , 1350 and $1400{ }^{\circ} \mathrm{C}$ are shown in Figure 8. From the XRD patterns it can be observed that $\mathrm{TiO}_{2}$ reflections are only observed in the samples treated at $1300{ }^{\circ} \mathrm{C}$ whereas for the composite sintered at $\geq 1350{ }^{\circ} \mathrm{C}$, no diffraction peaks of $\mathrm{TiO}_{2}$ are detected, indicating that all of $\mathrm{TiO}_{2}$ reacted with $\mathrm{Al}_{2} \mathrm{O}_{3}$ during SPS process to form $\mathrm{Al}_{2} \mathrm{TiO}_{5}$ at very low temperature.

The XRD of the materials sintered by conventional method at $1400{ }^{\circ} \mathrm{C}$ is shown in Figure 9. Aluminium titanate has already formed at $1400{ }^{\circ} \mathrm{C}$ but not completely. The maximum temperature, therefore, would be limited to $1400^{\circ} \mathrm{C}$, as the titania has already reacted to form aluminium titanate at this temperature, even though a very low concentration of unreacted titania still remains according to the above XRD analysis. Molina et al. observed that the complete reaction sintering to form A-AT composites occurred at $1500{ }^{\circ} \mathrm{C}$ [10]. This results contrast with those of SPS where all of $\mathrm{TiO}_{2}$ reacted with $\mathrm{Al}_{2} \mathrm{O}_{3}$ during sintering process at $\geq 1350{ }^{\circ} \mathrm{C}$ to form $\mathrm{Al}_{2} \mathrm{TiO}_{5}$.

Table 1 compares the thickness and hardness of the films obtained by conventional sintering (CS) and spark plasma sintering (SPS), as well as the densities, of the front thicker layers. A meaningful difference can be observed between the relative densities of the conventionally sintered samples and those prepared by SPS. At $1300{ }^{\circ} \mathrm{C}$, the density of the SPS sample was significantly higher than that of the CS samples. At this temperature if we compare the samples sintered by SPS with 1 min of dwelling time and CS with $2 \mathrm{~h}$ of dwelling time, the SPS sample has a density enhancement up to $6 \%$ (from $91.9 \%$ to $97.3 \%$ ) in a shorter time. On increasing the temperature to $1400{ }^{\circ} \mathrm{C}$ a significant 
improvement in densification is observed in the SPS samples $\sim 99 \%$. Fully dense specimens were, therefore, obtained at significantly lower sintering times by SPS.

The rapid densification of samples by SPS is attributed to the enhanced densification rate due to mechanisms such as particle rearrangement and the breaking up of agglomerates aided by applied pressure and faster heating rates. By rearrangement of particles, the SPS process also impedes the pore size increasing which was generally observed in the first and intermediate stages of sintering. Further, applied electric field also promotes the diffusion of ions and vacancies, which enhance the sintering rate. Also, the thickness observed in the samples sintering by SPS are low than CS, this is due to the applied pressure at the same time to the heating rates and high temperature are enhanced. Therefore, SPS is an excellent method to improvement the density of the EPD samples.

Hardness of SPS and conventionally fabricated A-AT EPD materials are presented in Table 2 as a function of sintering temperature. The experimental measurements show that the highest hardness values were achieved at $1350{ }^{\circ} \mathrm{C}$. As indicated in this table, the highest level of hardness belonged to the specimens sintered by the SPS method. In the CS sample sintered at 1350 and $1400{ }^{\circ} \mathrm{C}$, the values are close to the sample by SPS sintered at $1300{ }^{\circ} \mathrm{C}(\sim 17.5 \mathrm{GPa})$. The maximum hardness achievement is for the sample sintered by SPS at $1350^{\circ} \mathrm{C}, 18.2 \mathrm{GPa}$. These values are of the same order reported in the literature for similar materials. However, it must be noted that the present work refers to self-sustained films instead of bulk bodies. With this consideration in mind, the values obtained herein give a promising alternative to obtain thick coatings and films with relatively high mechanical performance. Typical hardness values reported for alumina materials conventionally sintered at $1450{ }^{\circ} \mathrm{C}$ and $1550{ }^{\circ} \mathrm{C}$ are 17.3 and $16.8 \mathrm{GPa}$, respectively. The hardness of materials AAT with 10 vol.\% AT treated at the same conditions were reported to be $15.5 \mathrm{GPa}$ [24]. Yang et al [7] reported the preparation of A-AT composites with relative ratio 87-13 using nanopowders and SPS and the hardness determined for this material was $16.7 \mathrm{GPa}$. Botero et al. [25] have recently reported the effect of AT addition on the mechanical properties of A-AT materials. These authors prepared monolithic alumina and studied the effect of the addition of 5 and 10 vol.\% AT after 
sintering at $1500^{\circ} \mathrm{C} / 1 \mathrm{~h}$. The hardness obtained by nanoindentation tests was $26.5,29.8,22.1 \mathrm{GPa}$, respectively. In the present work the films prepared by EPD have an expected composition of A-AT with a relative ratio $70-30$, that is, the final AT content is higher than that used in those papers. Hence, whereas those papers are expected to be constituted by non-microcracked material the films prepared herein with higher AT content are expected to present extensive microcracking, which is benefitial for thermal shock applications [26].

In summary, the hardness values of the SPS materials are higher than those of the conventionally fabricated materials that were processed at the same temperature with $2 \mathrm{~h}$ of dwelling time. This is due to better and faster densification of the SPS specimens.

The FE-SEM micrographs of the fracture surface of A-AT ceramic composites obtained by CS and SPS at different temperatures are shown in Figure 10 and Figure 11, respectively.

The main difference between samples sintered by CS and SPS is the size and shape of the alumina grains. Ceramics prepared by SPS exhibit full densification with absence of pores and with homogeneous-grained growth of $\mathrm{Al}_{2} \mathrm{O}_{3}$. The composite consolidated at $1300{ }^{\circ} \mathrm{C}$ (Fig. 11a) shows a narrow grain size distribution ranging from $0.8 \mu \mathrm{m}$ to $1.2 \mu \mathrm{m}$. When the composites are sintered at higher temperatures (Fig. $11 \mathrm{~b}$ and $11 \mathrm{c}$ ), most $\mathrm{Al}_{2} \mathrm{O}_{3}$ grains are located in the range of 1.2-1.6 $\mu \mathrm{m}$. As it has been observed, the $\mathrm{Al}_{2} \mathrm{O}_{3}$ grain size has a homogeneous distribution, ranging from $0.8 \mu \mathrm{m}$ to $1.6 \mu \mathrm{m}$, and the fracture mode observed in these materials is predominantly transgranular.

Only small microstructural differences between the composites obtained by CS are observed at this magnification (Fig. 10). All materials presented similar microstructural features with exaggerated alumina grain growth $(\sim 2 \mu \mathrm{m})$. It is well known that titania accelerates the mass transport mechanisms in alumina and could lead to exaggerated grain growth at high temperature when small amounts of titania are present [13]. However, the specimens sintered by SPS technique with applied pressure and fast heating rates, show a homogeneous grain growth due to different diffusion mechanism. This fact leads to better mechanical properties. 


\section{Conclusions}

In summary, concentrated optimized suspension of submicron sized $\mathrm{Al}_{2} \mathrm{O}_{3}$ and nanosized $\mathrm{TiO}_{2}$ powder have been prepared up to solid loading of 40 vol.\% by controlling the sonication time and the deflocculant content. Concentrated suspension was used to prepare self-sustaining thick films by EPD at constant current density using graphite electrodes. To maintain the stability of the nanophase of titania sintering was performed by conventional and spark plasma sintering at different temperatures $\left(1300-1400^{\circ} \mathrm{C}\right)$.

The density achieved to the samples sintered by SPS is very high ( $99 \%$ TD) and the alumina average grain size ranges in all composites were about 1.2-1.6 $\mu \mathrm{m}$. It must be noted that the full reaction of $\mathrm{Al}_{2} \mathrm{O}_{3}$ and $\mathrm{TiO}_{2}$ to obtain $\mathrm{Al}_{2} \mathrm{O}_{3} / \mathrm{Al}_{2} \mathrm{TiO}_{5}$ ceramic composites occurred at very low temperature, $1350^{\circ} \mathrm{C}$. Therefore, the hardness obtained is excellent (18.2 GPa). This improvement is due not only to the nanostructured composite powders obtained but also to the fast sintering technique (SPS), which allow us to obtain full dense and homogeneous microstructures.

\section{Acknowledgements}

This study has been supported by the Spanish Ministry of Science and Innovation MAT200914369-C02-01 and MAT2009-14144-C03-02. A. Borrell, acknowledges the Spanish Ministry of Science and Innovation for her Juan de la Cierva contract (JCI-2011-10498) and the Generalitat Valenciana for the BEST/2012/302 grant and the financial support for ACOMP/2012/166.

\section{References}

[1] R. Uribe, C. Baudín, J. Am. Ceram. Soc. 86 (2003) 846-50.

[2] N.P. Padture, J.L. Runyan, S.J. Bennison, L.M. Braun, B.R. Lawn, J. Am. Ceram. Soc. 76 (1993) 2241-2247.

[3] J. Bartolomé, J. Requena, J.S. Moya, M. Li, F. Guiu, Acta Mater. 44 (1996) 1361-1370.

[4] B. Freudenberg, A. Mocellin, J. Am. Ceram. Soc. 70 (1987) 33-38. 
[5] H.A.J. Thomas, R. Stevens, Microstructure development during the reaction sintering of alumina and titania to produce aluminium titanate, in: R. Stevens, D. Taylor (Eds.), Complex microstructures: meeting of the basic science sections held at Durban University. The Institute of Ceramics, Stoke-on Trent, UK, 1989, pp. 117-122.

[6] S. Bueno, R. Moreno, C. Baudín, J. Eur. Ceram. Soc. 24 (2004) 2785-2791.

[7] Y. Yang, Y. Wang, W. Tian, Y. Zhao, J. He, H. Bian, Z. Wang, J. Alloys Comp. 481 (2009) $858-862$

[8] Y. Wang, Y. Yang, Y. Zhao, W. Tian, H. Biana, J. He, Wear 266 (2009) 1051-1057.

[9] M.I. Nieto, C. Baudín, I. Santacruz, Ceram. Int. 37 (2011) 1085-1092.

[10]T. Molina, M. Vicent, E .Sánchez, R. Moreno, Mater. Res. Bull. 47 (2012) 2469-2474.

[11] A. Borrell, M.D. Salvador, V.G. Rocha, A. Fernández, T. Molina, R. Moreno, Comp. Part B, 47 (2012) 255-259.

[12]B. Ferrari, R. Moreno, J. Eur. Ceram. Soc. 30 (2010) 1069-1078.

[13] J.H. Dickerson, A.R. Boccaccini, Electrophoretic deposition of nanomaterials. Springer, New York, 2012.

[14] T. Molina, M. Vicent, E. Sánchez, R. Moreno, Key Eng. Mater. 507 (2012) 203-207.

[15] Z.A. Munir, U. Anselmi-Tamburini, M. Ohyanagi, J. Mater. Sci. 41 (2006) 763-777.

[16] M. Vicent, E. Sánchez, I. Santacruz, R. Moreno, J. Eur. Ceram. Soc. 31 (2011) 1413-1419.

[17] C.A. Gutiérrez, R. Moreno, J. Mater. Sci. 35 (2000) 5867-5872.

[18] ASTM File 42-1468. Database PDF (Powder Diffraction File).

[19] ASTM File 21-1272. Database PDF (Powder Diffraction File).

[20] ASTM File 21-1276. Database PDF (Powder Diffraction File).

[21] ASTM File 26-0040. Database PDF (Powder Diffraction File).

[22] B. Ferrari, R. Moreno, J. Eur. Ceram. Soc. 27 (2007) 549-556.

[23] B. Ferrari, R. Moreno, J. Electrochem. Soc. 147 (2000) 2987-2992.

[24] S. Bueno, PhD Thesis, Universidad Autónoma Madrid, Spain, 2005. 
[25] C.A. Botero, E. Jiménez-Piqué, C. Baudín, N. Salán, L. Llanes, J. Eur. Ceram. Soc. 32 (2012) $3723-3731$.

[26] S. Bueno, R. Moreno, C. Baudín, J. Eur. Ceram. Soc. 25 (2005) 847-856.

\section{Figure captions:}

Figure 1. Flow curves of AT suspensions prepared to solid loadings of 30 (a), 40 (b) and, 50 vol.\% (c) and different sonication times.

Figure 2. Variation of mass per unit area of deposits obtained for suspension with solid loadings of 30, 40 and, 50 vol.\% and current intensities of 1,3 y $5 \mathrm{~mA}$ (i.e current densities of $0.28,0.83$ and $\left.1.39 \mathrm{~mA} \mathrm{~cm}^{-2}\right)$.

Figure 3. FE-SEM pictures of cross-sections of the A-AT self-sustained films obtained from the different solids loadings at both the front and the back sides of the working electrodes obtained at $10 \mathrm{~mA}$ (current density of $1.39 \mathrm{~mA} \mathrm{~cm}^{2}$ ) for $10 \mathrm{~min}$.

Figure 4. Variation of thickness between the front and the back layers deposited at a current density of $1.39 \mathrm{~mA} \mathrm{~cm}{ }^{2}$ as a function of deposition times after sintering at $1400{ }^{\circ} \mathrm{C}$.

Figure 5. FE-SEM microstructure of front (a) and back (b) surfaces of deposits obtained at a current density of $1.39 \mathrm{~mA} \mathrm{~cm}^{2}$ for $10 \mathrm{~min}$ and sintered at $1400^{\circ} \mathrm{C}$.

Figure 6. FE-SEM picture of a surface of a conventionally sintered material (40 vol.\% EPD 5mA$10 \mathrm{~min}$ ) and EDX analysis of the two phases present.

Figure 7. Cross-sectional FE-SEM pictures of the film deposited on the front surface (a) and on the back surface (b) obtained from 40 vol.\% solid suspension after a thermal treatment by SPS at 1400 ${ }^{\circ} \mathrm{C}$.

Figure 8. XRD patterns of the $\mathrm{Al}_{2} \mathrm{O}_{3} / \mathrm{Al}_{2} \mathrm{TiO}_{5} \mathrm{EPD}$ ceramic composites sintered by SPS at $1300{ }^{\circ} \mathrm{C}$, $1350{ }^{\circ} \mathrm{C}$ and, $1400{ }^{\circ} \mathrm{C}$.

Figure 9. XRD patterns of the $\mathrm{Al}_{2} \mathrm{O}_{3} / \mathrm{Al}_{2} \mathrm{TiO}_{5}$ EPD ceramic composites sintered by $\mathrm{CS}$ at $1400^{\circ} \mathrm{C}$.

Figure 10. FE-SEM micrographs of fracture surface of $\mathrm{Al}_{2} \mathrm{O}_{3} / \mathrm{Al}_{2} \mathrm{TiO}_{5}$ ceramic composites obtained 
by CS at different temperatures: (a) $1300{ }^{\circ} \mathrm{C}$, (b) $1350{ }^{\circ} \mathrm{C}$ and, (c) $1400{ }^{\circ} \mathrm{C}$.

Figure 11. FE-SEM micrographs of fracture surface of $\mathrm{Al}_{2} \mathrm{O}_{3} / \mathrm{Al}_{2} \mathrm{TiO}_{5}$ ceramic composites obtained by SPS at different temperatures: (a) $1300{ }^{\circ} \mathrm{C}$, (b) $1350{ }^{\circ} \mathrm{C}$ and, (c) $1400{ }^{\circ} \mathrm{C}$. 